九州大学学術情報リポジトリ

Kyushu University Institutional Repository

\title{
Development of Hybrid Kiln Drying System with Radio Frequency Heating for the Sugi Heart Timber
}

Piao, Jinji

Graduate School of Bioresource and Bioenvironmental Sciences, Kyushu University

Fujimoto, Noboru

Faculty of Agriculture, Kyushu University

Yamamoto, Yasushi

Yamamoto Vinita Co.

Nagata, So j i

Yamamoto Vinita Co.

https://doi.org/10.5109/9292

出版情報：九州大学大学院農学研究院紀要. 52 (1)，pp.117-121，2007-02-28. Faculty of Agriculture, Kyushu University

バージョン :

権利関係 : 


\title{
Development of Hybrid Kiln Drying System with Radio Frequency Heating for the Sugi Boxed Heart Timber
}

\author{
Jinji PIAO $^{1}$, Noboru FUJIMOTO*, Yasushi YAMAMOTO ${ }^{2}$ and Soji NAGATA ${ }^{2}$ \\ Laboratory of Wood Technology, Division of Biomaterial Science, Department of Forest and Forest \\ Products Sciences, Faculty of Agriculture, Kyushu University, \\ Fukuoka 812-8581, Japan \\ (Received November 10, 2006 and accepted December 1, 2006)
}

\begin{abstract}
In this study, proper applied stage of the radio-frequency (RF) heating during kiln drying based on the quality concerning the surface checks of the boxed heart timbers was examined.

At the stage of the RF heating the moisture contents decreased clearly at the internal parts of timbers. The surface stress of the sugi (Cryptomeria japonica D. Don) boxed heart timber changed into the compression stress by the RF heating in any drying stage. The surface checks increased according to the decrease of the moisture content. However, the increase of the area and the width of the surface checks in the Link 3 were comparatively low, and the quality of these boxed heart timbers seemed relatively good. The amount of electric energy of RF heating in the Link 3 was fewer than that in the Link 1, 2.
\end{abstract}

\section{INTRODUCTION}

The adequate drying of sugi boxed heart timbers for the structural members with large dimension requires a long time in general because the moisture content (MC) at the inner part does not decrease easily.

Fang et al. (2001) reported radio-frequency/ vacuum (RF/V) drying method could dry 165-240 mm diameter roundwoods from their sapwood MC of over $80 \%$ to a final MC of less than $25 \%$, in less than 16 hours. Furthermore, RF/V drying produced poles with a uniform final MC.

Moisture flow characteristics of thick hemlock lumber during RF/V drying were examined (Zhang et al., 1997). The results showed that short specimens dried faster than long ones at MCs above the fiber saturation point.

Avramidis et al. (1994) had reported that thick western redcedar can be dried by RF/V without degrade. Furthermore, it was established that very high temperature and significant pressure gradients would develop in the longitudinal direction of the boards. And both gradients were affected by the electrode voltage and significantly contributed to the high drying rates achieved with this method.

As mentioned above, the effectiveness of the RF heating and vacuum drying in the improvement of a drying speed had been shown.

Recently, the hybrid drying system of RF heating and conventional kiln air heating has been commercialized in Japan for these heavy timbers. Even the inner layer can be dried adequately in a short term by this system. Especially, large tension set on the surface layer of the boxed heart timber can be formed with high

\footnotetext{
1 Laboratory of Wood Technology, Department of Forest and Forest Products Sciences, Graduate School of Bioresource and Bioenvironmental Sciences, Kyushu University

2 Yamamoto Vinita Co., Ltd

* Corresponding author (E-mail: fujipon@agr.kyushu-u.ac.jp)
}

temperature and low humidity condition at the initial stage of drying, and the surface checks are suppressed (Yoshida et al., 2000).

However, it is necessary to develop the application system of RF heating. In this study, proper applied stage of the RF heating was examined based on the quality concerning the surface checks, which is the most important defect in the quality of the dried timber.

\section{MATERIALS AND METHODS}

\section{Materials}

Drying test was carried out on 9 sugi boxed heart square timbers of $120 \mathrm{~mm} \times 120 \mathrm{~mm} \times 500 \mathrm{~mm}$ (Longitudinal direction). Before test, $20 \mathrm{~mm}$ thick cross sections at the points of $50 \mathrm{~mm}$ from the ends of timbers were sampled, and initial MC distributions in the cross section were measured by oven dried method. The rest $430 \mathrm{~mm}$ specimens were used for the drying test after coating the both ends by silicon. Three specimens were dried in each system method.

\section{Drying methods}

Three drying systems, which are conventional kiln drying of D. B. T. $80^{\circ} \mathrm{C}$ and W. B. T. $75^{\circ} \mathrm{C}$ linking with $\mathrm{RF}$ heating in periods to 30\% MC (Link 1), 30\% MC to 20\% MC (Link 2) and 20\% MC to 15\% MC (Link 3), were pursued in this research (Table 1).

Figure 1 shows the arrangement method of the specimens during $\mathrm{RF}$ heating. These specimens were placed between a charged and a grounded electrode under atmospheric pressure. For measuring the tem-

Table 1. Hybrid kiln drying methods of Link 1, 2 and 3

\begin{tabular}{clcc}
\hline Moisture content & Green 30\% & $30 \% \sim 20 \%$ & $20 \% \sim 15 \%$ \\
\hline Link 1 & RF heating & \multicolumn{2}{c}{ Kiln drying } \\
Link 2 & Kiln drying & RF heating & Kiln drying \\
Link 3 & \multicolumn{2}{c}{ Kiln drying } & RF heating \\
\hline
\end{tabular}




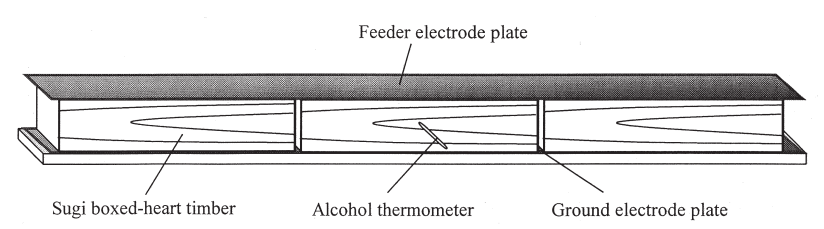

Fig. 1. Arrangement of the specimens in RF heating.

perature of the specimen during RF heating, center specimen of three timbers was drilled a hole, and put an alcohol thermometer and sealed with epoxy resin. The temperature of the specimen was controlled at $102^{\circ} \mathrm{C}$ by on-off automatic operation of the RF.

The RF heating was operated only daytime, and this stage took three days for any drying system (Link 1, 2 and 3). The changes of the specimen temperature during the RF heating in daytime are shown in Fig. 2. In any drying system, the rising speed of the specimen temperature by the RF heating is fast in the first day, and slow in the third day. It is supposed that the

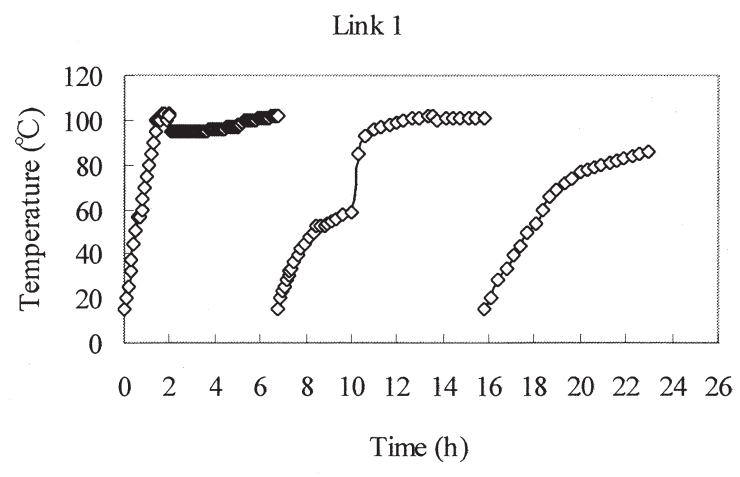

Link 2
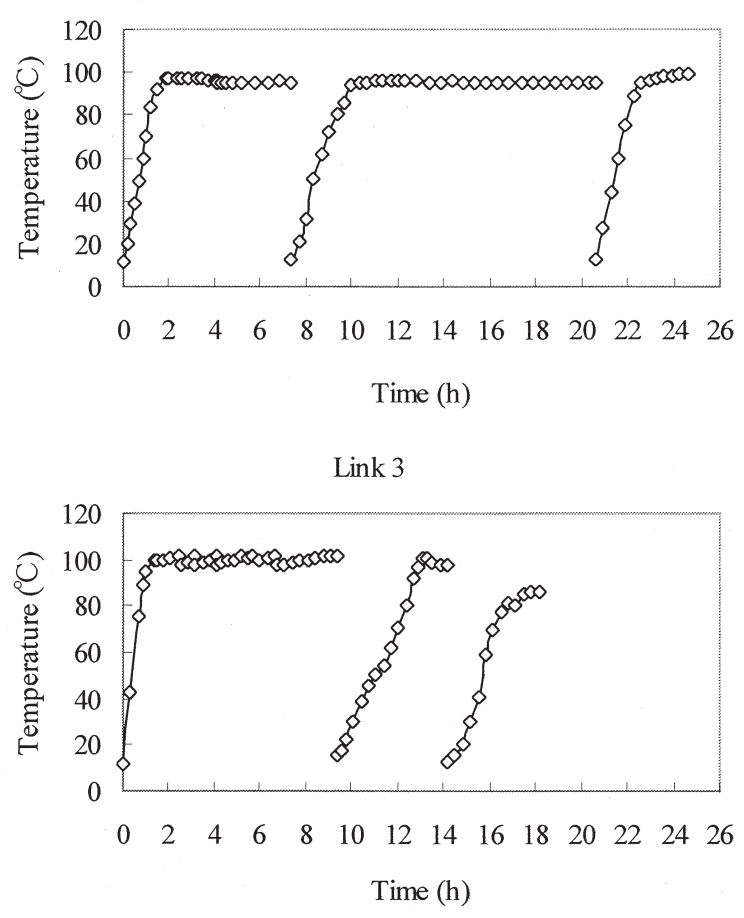

Fig. 2. Temperature changes of the timbers during $\mathrm{RF}$ heating. existence of water with a high dielectric has an influence on the energy conversion efficiency.

\section{Measurements}

MC distributions of the cross section (oven dry method, divided 36 pieces in the cross section), surface checks and released strains in the direction of the width were measured at each drying stage.

\section{RESULTS AND DISCUSSION}

\section{Drying curve}

Figure 3 shows dry curves in the Link 1, 2 and 3 . In every drying test, a rapid decrease of MC was found in the stage of the RF heating. The decrease of MC at the early stage $\mathrm{RF}$ heating is larger than that at the latter stage RF heating. However, there was no large difference of the overall drying time in the Link 1,2 and 3.

Link 1

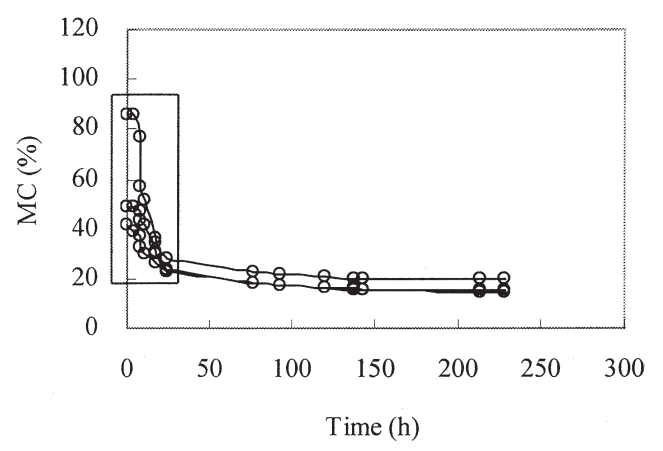

Link 2

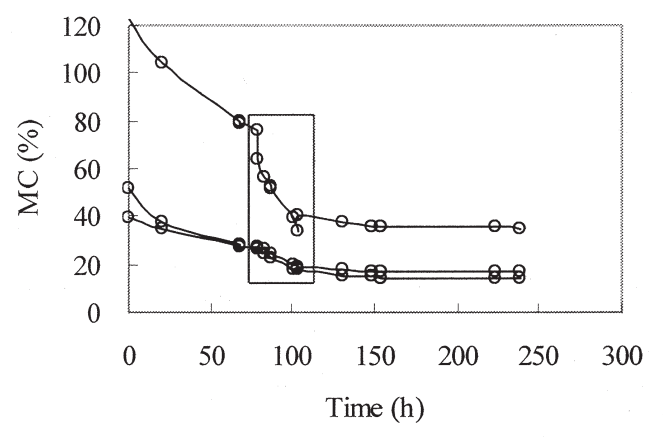

Link 3

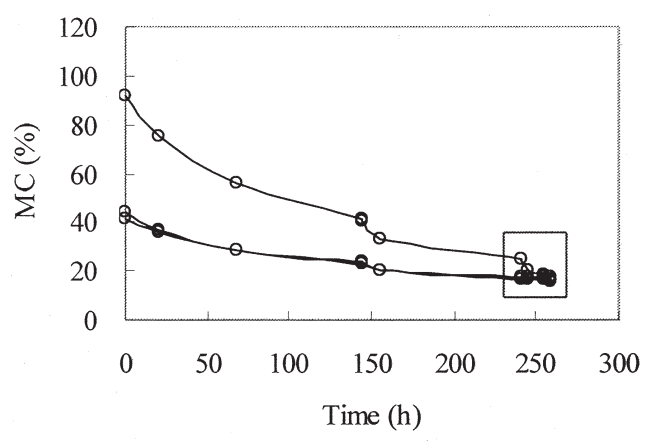

Fig. 3. Drying curve of hybrid kiln drying systems with RF heating stage.

Note: Square mark: RF heating stage. 


\section{MC distribution}

MC distributions in the cross section during drying on the Link 1, 2 and 3 are shown in Fig. 4. MCs of the outer layers decreased greatly during drying with air heating. On the other hand, MCs decreased clearly at the internal layers of timbers at the stage of the $\mathrm{RF}$ heating. Especially, MCs of the internal parts have lowered more than those in the outer parts in the Link 1 and 2. The surface stress in Link 3 has also changed into the compression stress after the third stage with the $\mathrm{RF}$ heating, even though MCs in the outer part were lower than the inner part. This reason might be a large drying set in tension on the surface layer of the boxed heart timber, which was dried with air heating in the first and the second stage.

\section{Surface stress}

Figure 5 shows the surface released strains of sugi boxed heart timbers during drying on the Link 1, 2 and 3. After the first stage of drying with $\mathrm{RF}$ heating in the Link 1, the surface stress was compression. But the stress changed to tension after the second stage of drying with air heating. This tension stress became larger in the third stage drying with air heating. In the Link 2, the surface tension stress of the timber after the first stage with air heating changed into compression stress during the second stage with RF heating. However, it has changed into large tension stress in the third stage with air heating again. On the other hand, in the Link 3 the tension stress after the first and second stage drying with air heating has changed into the compression stress at the end of drying. Thus, the surface stress of the sugi boxed heart timber changes into the compression stress by the RF heating in any drying stage. It was presumed that this reason was MC decrease at the inner layer by the concentrated heating



Fig. 4. MC distributions in cross section of the boxed-heart timbers. Note: RFH: Radio-frequency heating. 


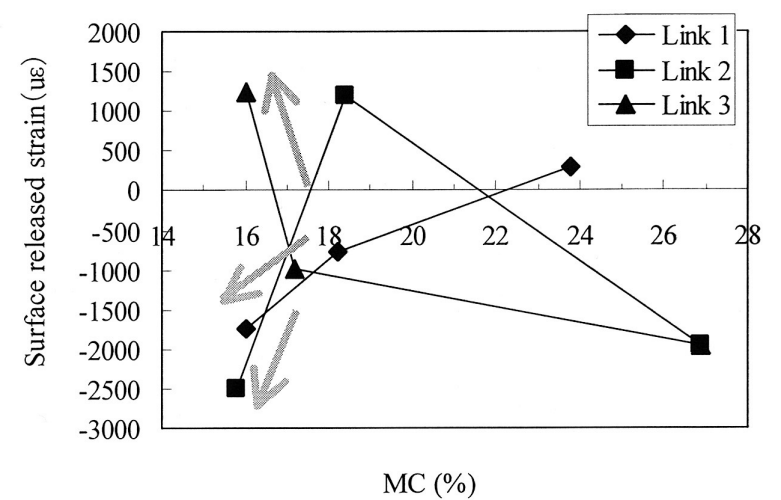

Fig. 5. Change of surface released strain of the boxed-heart timber.

by the RF. However, it seemed that the drying system of the Link 3 was desirable to maintain the quality stability against the surface checks for the dried boxed heart timbers.

\section{Surface checks}

Area, length and width of surface checks of the specimens immediately after drying and at the 40th day afterwards are shown in Fig. 6. MCs of all specimens decreased for leaving in the room after drying. The surface checks increased according to the decrease of MC. However, the increase of the width and the area of the surface checks in the Link 3 were comparatively low, and the quality of these boxed heart timbers seemed desirable.

\section{Drying time and multiplication electric power}

Drying time and multiplication electric power in these drying systems were shown in Table 2. Drying time in the kiln with air heating in the Link 3 was longer than that in the Link 1 and 2. On the other hand, the amount of electric energy of the RF heating in the Link 3 was fewer than that in the Link 1 and 2. This reason might be the lower thermal capacity of the timbers at the third drying stage with low MC.

\section{CONCLUSIONS}

Hybrid kiln drying with RF heating was examined in
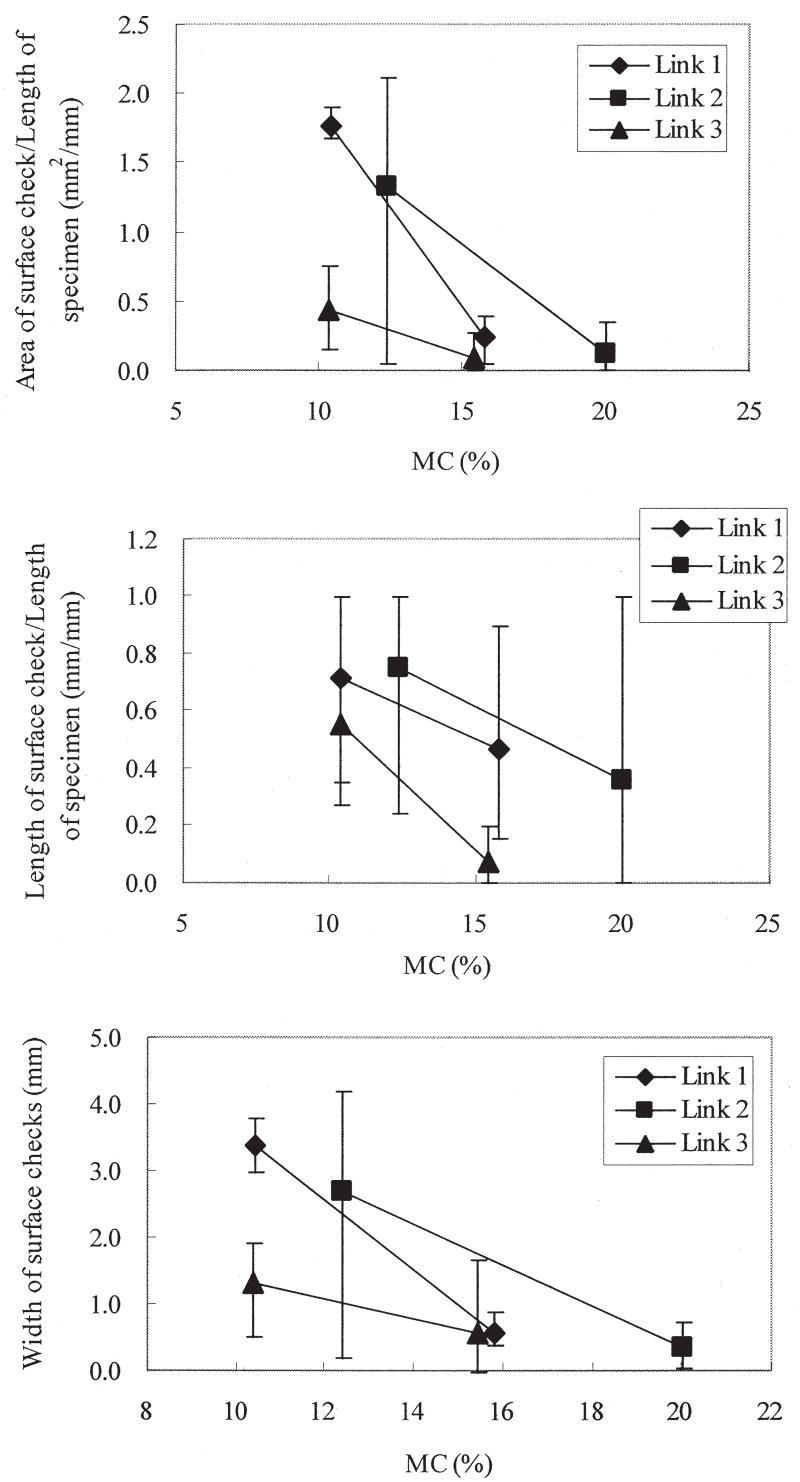

Fig. 6. Change of surface check extent of the timbers left in the room for 40 days after the hybrid kiln drying.

this study.

When the RF heating was applied to initial and the middle term of the drying process (Link 1 and 2), the decrease of MC by the RF heating is remarkable. However, there was no difference of entire drying time among Link 1,2 and 3. The surface check of Link 3 was

Table 2. Drying time and multiplication electric power of hybrid kiln drying (Link 1,2 and 3)

\begin{tabular}{|c|c|c|c|c|c|c|}
\hline & Specimens & $\begin{array}{l}\text { MC before } \\
\text { drying (\%) }\end{array}$ & $\begin{array}{c}\text { MC after } \\
\text { drying (\%) }\end{array}$ & $\begin{array}{l}\text { irradiation } \\
\text { time (h) }\end{array}$ & $\begin{array}{l}\text { multiplication electric } \\
\text { power (kwh) }\end{array}$ & $\begin{array}{l}\text { Kiln drying } \\
\text { time }(\mathrm{h})\end{array}$ \\
\hline \multirow{3}{*}{ Link 1} & $1-1$ & 49.9 & 14.9 & \multirow{3}{*}{22.9} & \multirow{3}{*}{7.64} & \multirow{3}{*}{204} \\
\hline & $1-2$ & 79.6 & 15.5 & & & \\
\hline & $1-3$ & 44.9 & 17 & & & \\
\hline \multirow{3}{*}{ Link 2} & $2-1$ & 50.2 & 15.6 & \multirow{3}{*}{24.6} & \multirow{3}{*}{7.90} & \multirow{3}{*}{214.7} \\
\hline & $2-2$ & 107.6 & 28.6 & & & \\
\hline & $2-3$ & 41.9 & 15.9 & & & \\
\hline \multirow{3}{*}{ Link 3} & $3-1$ & 43.6 & 15.4 & \multirow{3}{*}{18.2} & \multirow{3}{*}{5.27} & \multirow{3}{*}{240.7} \\
\hline & $3-2$ & 91.3 & 14.4 & & & \\
\hline & $3-3$ & 41.6 & 16.6 & & & \\
\hline
\end{tabular}


comparatively small because of tension set formed with the kiln drying at the early stage. Moreover, the RF energy consumption in Link 3 was fewer than in Link 1, 2

From these results, it was guessed that the hybrid drying system of Link 3 with the RF heating at the latter stage was relatively desirable.

\section{REFERENCES}

Avramidis, S., F. Liu, B. J. Neilson 1994 Radio-frequency/ vacuum drying of softwoods: drying of thick western redcedar with constant electrode voltage. Forest Products Journal, 44(1): 41-47

Fang, F., J. N. R Ruddick, S. Avramidis 2001 Application of radio-frequency heating to utility poles. Part1. Radiofrequency/vacuum drying of roundwood. Forest Products Journal, 51(7/8): 56-60

Yoshida, T., T. Hashizume, N. Fujimoto 2000 High-temperature drying characteristics on boxed-heart square timber of karamatsu and sugi - Influences of high temperature conditions with low humidity on drying properties -. MOKUZAI KOGYO, 55(8): $357-362$

Zhang, L., S. Avramidis, S. G. Hatzikiriakos 1997 Moisture flow characteristics during radio frequency vacuum drying of thick lumber. Wood Science and Technology, 31: 265-277 